Military Technical College

Kobry El-Kobba

Cairo, Egypt

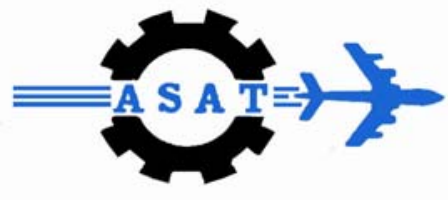

12-th International Conference

on

Aerospace Sciences \&

Aviation Technology

\title{
QUASI-STATIC INDENTATION OF DOUBLE SKIN COMPOSITE PANELS
}

MOHAMEDIEN A.R. ${ }^{*}$ AGOUR A.A. ${ }^{*}$, OMER A.A. ${ }^{*}$ and Yones M.M.*

\begin{abstract}
Double skin composite (DSC) is a structural system of steel plates connected to a sandwiched concrete core with welded stud shear connectors. Shear studs are welded to the plates at regular centers and act as connectors for the concrete core. The final structure acts compositely with the steel skins carrying either tension or compression, the concrete core carrying some compression and the connectors transferring both horizontal shear between layers and vertical shear across the section. In this research an investigation of double skin composite panels behavior when subjected to quasi-static loading was done. A series of quasi-static tests were used to analysis deformation and energy absorption capacity of such system when perforated by rigid penetrator with conical nose shape. Research results showed that such elements are very effective in resisting quasi-static loads and have great ability of absorbing energy when subjected to perforation due to ductility of lower plate skin and vertical stiffness of lower shear studs.
\end{abstract}

KEYWORDS: Double skin composite, Bi-steel, Quasi-static test, Shear studs 


\section{Introduction}

Double skin composite (DSC) is a form of steel/concrete/steel sandwich construction in which the plates are connected by bars, which are welded at both ends simultaneously. Manufactured units are taken to site, joined by welding, and filled with concrete. The bar/plate connections are subject to bar tension, bar shear, bar bending and plate tension. The concrete acts with the compression plate and resists shear. The notion of sandwich construction, whereby the two skins resist bending and the core resists shear, is not new. For example, it is widely used for internal doors, and more recently in ships' steel partitions. The first proposed application of a steel/concrete/steel sandwich was for a submerged tube highway tunnel in North Wales, in 1986 [1]. The system was proposed by Tomlinson brothers, a Welsh consultancy. The proposed structure consisted of two inner steel shells and an outer shell. The inner and outer shells were to be connected by overlapping stud welded headed bars. The required length was beyond that of available studs designed for stud welding, so the length was to be increased by stud welding bars to the heads of bars welded to the shells. The design was taken to an advanced stage, and scale models were tested at Cardiff University.

The main problems face the usage of reinforced concrete to resist impact loading that may cause penetration or perforation of slabs in high rise buildings, shelters, military buildings,....etc are much smallness in ductility of concrete slabs and needing of big slab thickness or great reinforcing steel ratio in slab section [2]. Double composite (steel-concrete-steel) panels presented an excellent alternative solution of these problems due to its expected ductility. In the present paper a series of quasi-static tests were used to analysis deformation and energy absorption capacity of such system when perforated by rigid penetrator with conical nose shape. These tests include variation of upper and lower plate thickness, increasing degree of shear interaction between upper and lower plates, reducing the distribution density of upper stud connectors with the same degree of interaction between upper steel skin and concrete core. Results showed that such elements are very effective in resisting quasi-static loads and have great ability of absorbing energy when subjected to perforation due to ductility of lower plate skin and vertical stiffness of lower shear studs.

\section{Experimental Work Setup}

The quasi-static tests were done to capture the failure modes until perforation of tested panel is obtained. It is also used to estimate the change in energy absorbed due to change in different parameters. To achieve this experimental work a series of different panels was composed to study the role of each parameter independently; Theses parameters are top plate thickness, lower plate thickness, and degree of shear interaction in the upper plate, degree of shear interaction in the lower plate and the density of stud distribution in the upper plate. The dimensions of the specimens are chosen based on the available ultimate energy which can be obtained from the used machine and based on the regulations of detailing of composite steel-concrete structures. All panels are chosen of dimension $(1000 \mathrm{~mm} \times 1000 \mathrm{~mm})$ and all panels have unique concrete core thickness of $50 \mathrm{~mm}$ except in the pilot specimen the concrete core was $80 \mathrm{~mm}$. All upper and lower studs used in the specimens have dimensions of $8 \mathrm{~mm}$ in diameter of shank and $12 \mathrm{~mm}$ in diameter of stud head with 
$4 \mathrm{~mm}$ in thickness of stud head with total stud length of $35 \mathrm{~mm}$ except specimen (DSC5) had upper studs dimensions of $10 \mathrm{~mm}$ in shank diameter and $15 \mathrm{~mm}$ in stud head diameter with $5 \mathrm{~mm}$ in thickness of stud head, the same total stud length was used. Table (1) shows specifications of all specimens.

\subsection{Specimens Objectives}

Trial specimen (pilot test) was formed to investigate the general behavior under penetration and to setup the machine test rig. Specimen DSC1 was formed to study the parameter of increasing upper plate thickness while specimen DSC2 was formed to study the parameter of increasing lower plate thickness. Specimen DSC3 used to study the parameter of increasing degree of shear interaction between upper steel skin and concrete core. Furthermore Specimen DSC4 was formed to study the parameter of increasing degree of shear interaction between lower steel skin and concrete core. Specimen DSC5 was formed to study the parameter of reducing the distribution density of upper shear stud connectors with the same degree of interaction between upper steel skin and concrete core. During experiments only one parameter was changed while the other parameters were kept constant. Fig. (1) shows preparation of all specimens.

\subsection{Materials}

The concrete mix was designed to produce normal strength plain concrete with average normal cube strength as given from tests of $350 \mathrm{Kg} / \mathrm{Cm}^{2}$ and the constituent materials were as follows: Ordinary portland cement, Local gravel with $32 \mathrm{~mm}$ maximum nominal size , 2.66 specific gravity and $1.62 \mathrm{t} / \mathrm{m}^{3}$ volume weights. Medium type sand with 2.56 specific gravity and $1.66 \mathrm{t} / \mathrm{m}^{3}$ volume weights. Potable water was used, with $w / c$ ratio $=0.48$. A series of cold rolling thin normal mild profiled steel plates were used to compose the upper and lower skins of specimens. Steel plates thickness were varied from $2 \mathrm{~mm}$ to $4 \mathrm{~mm}$, while normal mild reinforcing steel bars of diameter $16 \mathrm{~mm}$ were formed to obtain the studs shear connectors.

\subsection{Specimens Control}

The property of concrete that is most quoted is its compressive strength (fc). Because of the high variation of concrete strengths, it is common to specify a characteristic concrete strength that is exceeded by $95 \%$ of ten samples of standard concrete cubes of dimension $(150 \mathrm{~mm} \times 150 \mathrm{~mm} \times 150 \mathrm{~mm})$ in the standard compressive strength test according to Egyptian code of practice No.(203). These ten concrete cubes were taken randomly from the concrete mixes which were prepared for the concrete core of all specimens during casting the specimen core. All ten concrete cubes were tested under standard calibrated compression machine till cracks of compression failure were appeared, and then compression strength of each cube was recorded to obtain the characteristic compression strength of the used concrete. Profiled steel sheeting used in composite profiled slabs is manufactured by cold rolling thin steel plates into an appropriate shape. The cold-rolling process tends to increase the yield stress. The yield stress was of $3500 \mathrm{Kg} / \mathrm{cm} 2$ and ultimate stress $4200 \mathrm{Kg} / \mathrm{cm} 2$. The elastic modulus was considered $21000 \mathrm{Kg} / \mathrm{cm} 2$. 


\section{Quasi-static Test}

A series of quasi-static tests were done for specimens (pilot specimen - DSC5) to capture the failure modes of such composite panels under penetration phenomena and to get an estimated value of the absorbed energy by each panel. Quasi-static test was a suitable technique for this objective; the rate of loading was very small to avoid the effect of acceleration during recording results of reaction forces in penetration phases and to relax the strain of both steel skins and concrete core until complete perforation was occurred. The composite panels were conducted using a $400-\mathrm{KN}$ capacity testing machine, the testing machine was provided with force head which was controlled by a hydraulic system to control the loading rate. The machine was fabricated such that two moveable I-shape beams carry the frame which support specimen. To achieve the objective of quasi-static test, complete perforation was an essential need which leads to fabrication of a new indenter nose shape that verified complete perforation with the allowable machine load capacity. Conical nose shape was an ideal solution to verify perforation with the small load capacity of machine [3]. In order to fabricate such conical nose shape, a cylinder steel bar of diameter $150 \mathrm{~mm}$ and $500 \mathrm{~mm}$ length was formed to obtain the suitable conical shape as shown in Fig. (2). A perfect clamping system for specimens to reduce the ability of lower and upper steel plate slippage was also an essential to reduce the need of great energy that may exceeds the available ultimate load capacity of testing machine. In order to verify this fixation end conditions, two frames were fabricated using steel angles (70x70x 6) $\mathrm{mm}$, one frame was welded to upper steel plate and another was welded to lower steel plate, while both frames were connected together by welding pieces of the same used angle at upper frame and using a bolt of diameter $20 \mathrm{~mm}$ which was tied in the web of machine frame as shown in Fig. (3). Force transducer was used to measure digitally the reaction force during perforation of specimens while dial gauge was used to measure displacement of machine head as shown in Fig. (4). Perforation of upper and lower steel skins obtained experimentally is shown in Fig. (5). All specimens were tested with concentrated applied load in the central area of the panel by conical nose shape indenter. A gradual loading was applied with gradual recording of reaction force and displacement of machine head during penetration and visual observations with incremental recording each $250 \mathrm{Kg}$ is obtained The test was finished when the rigid indenter perforate the total depth of each specimen. Initial reading of zero setting for all instruments was used to avoid reading variation faults and to take relative readings.

\section{Analysis of Experimental Work}

For all specimens reaction force and indenter displacement were recorded till complete perforation has been occurred. The results of reaction force and indenter displacement were plotted for each specimen to investigate the behavior of DSC panels under penetration. Fig. (6) shows this relation for pilot-test specimen. The obtained relation was divided into three parts $A, B$ and $C$ which described for all specimens as: Zone A started from zero loading till a drop in reaction force recording, which observed when complete perforation of upper steel skin occurred. This zone represented the amount of energy absorbed by upper steel skin. Zone B started from the next increasing in reaction force till another drop in reaction force reading, which observed when complete perforation of concrete and lower steel skin w obtained. This zone represented the amount of energy absorbed by concrete core and lower 
steel skin. Zone $C$ started from the end of zone $B$ till a zero reading of reaction force was recorded, which indicated a complete perforation of panel total thickness. This part represented the amount of energy absorbed by friction between panels and indenter after complete perforation occurred and this part was ignored since all elements of panels had failed. Fig. (7) shows the recorded results of reaction force versus indenter displacement for specimens $(1,2,3,4,5)$ respectively while Fig. (8) shows comparison between all specimens results. The analysis of each specimen results was done by grouping specimens into three groups. Group one consisted of specimens (1 and 2), group two consisted of specimens (3 and 4) and group three consisted of specimen 5 .

\section{Group One:}

Specimens of this group used to study the effect of increasing thickness of upper steel skin in specimen 1 and to study the effect of increasing thickness of lower steel skin in specimen 2, hence we compared between the two parameters. Specimen (1) upper steel skin perforated by force $25 \mathrm{KN}$, while in specimen (2) it was decreased to $15 \mathrm{KN}$, that showed increase in the energy absorbed by upper steel skin - area of (zone A) - by percentage about $60 \%$ by increasing thickness of upper steel skin from $2 \mathrm{~mm}$ to $4 \mathrm{~mm}$ only. It was clear that such increasing in upper plate thickness did not increase the total absorbed energy by weighted value versus increasing the cost and weight of panel, since upper plate resistance was dominated by small share from the total energy. Increasing the thickness of lower plate in specimen (2) with same value from $2 \mathrm{~mm}$ to $4 \mathrm{~mm}$ - increased in upper plate of specimen (1) showed great effect in the total absorbed energy of panel. The energy absorbed was increased by percentage about $25 \%$ (zone B), which showed ductility of such composite system depending on lower steel skin in-plane stiffness mainly not upper skin, although both of same material properties.

\section{Group Two:}

Specimens of this group used to study the effect of increasing degree of interaction between upper steel skin and concrete core in specimen (3) and increasing degree of interaction between lower steel skin and concrete core in specimen (4). In specimen (3) the increasing of degree of interaction between upper steel skin and concrete core had a good effect in increasing energy absorbed by upper steel similar to result of increasing in-plane stiffness of upper steel but larger with $60 \%$ and that because upper shear connectors in this case absorbed energy by carrying the relative slip between upper steel skin and core and acted as horizontal support to upper steel plate reducing its strain. Increasing upper degree of interaction also had a dominate effect in maximizing the total energy absorbed by panel cause all effect lay in (zone A). In specimen (4) the increasing of degree of interaction between lower steel skin and concrete core had a good effect in increasing energy absorbed by lower steel and concrete core similar to result of increasing in-plane stiffness of lower steel, which clarify the great role of lower shear studs comparing with upper shear connectors. The reason of this effect was that lower studs acted as vertical links to lower steel plate by means of anchorage in concrete core. The anchorage length (along stud length) absorbed energy by preventing vertical splitting of lower steel plate. 


\section{Group Three:}

The aim of this group was to study the effect of increasing degree of interaction between upper steel skin and concrete core in specimen (5) with low number of shear connectors to investigate the role of upper stud distribution when same degree of interaction was kept. In order to satisfy this case the upper shear resistance of specimen (3) was carried out with less number of studs. The results of specimen (3) and specimen (5) were compared. In specimen (5), increasing degree of interaction between upper steel skin and concrete core by same degree in specimen (3) but with less number of shear studs had bad effect on energy absorbed by zone (A). it was noticed that reducing number of shear studs reduced the energy absorbed by upper steel skin by $25 \%$ relative to that absorbed by specimen (3). That verified the analysis discussed in results of specimen (3). Upper shear studs helped upper steel skin in absorbing energy in case of enough number of studs were supplied to clarify its role as horizontal supports points to upper steel plate caused an enhancement in axial stiffness of plate beside carrying relative slipping between plate and core.

\section{Conclusions}

From the analysis of tests results in the present research work, the following conclusions can be drawn: New type of double skin composite pre-cast panel is presented. Such element can be easily manufactured and erected as temporary or permanent structures. These types of composite slabs can be used for different spans where usual form works are difficult to be used and the need for pre-cast elements is a must especially in military buildings. Effect of increasing upper plate thickness to face impact loading in double skin panels is very dominated and do not participate with valuable amount of energy absorbed compared with its stiffness increasing due to the presence of concrete brittle backing. Increasing lower plate thickness to face impact loading in double skin panels has a great and main role in controlling the amount of energy absorbed by such structures due to its ability to prevent concrete scabbing from impact rear face which relaxes strain rate of concrete while resisting penetration and due to presence of lower shear studs. Effect of increasing upper plate stiffness and lower plate stiffness can be similar to effect of providing an adequate number of upper and lower shear studs, as upper shear studs relax the strain rate of upper steel plate and lower shear studs relax strain rate and act as vertical links for lower steel plate when such panels subjected to impact loading.

\section{References}

[1] Wright, H.D., Oduyemi, T.O. and Evans, H. R. "The experimental behavior of double skin composite elements", J. of constructional steel researches. No. 19, pp 97-110, (1991)

[2] Kennedy, R. P., "A review of the procedures for the analysis and design of concrete structures to resist missile impact effects ". J. of Nuc. Eng. and Design, No. 37, pp183-203 (1976).

[3] Corran, R. S. et al "Impact loading of plates -an experimental investigation", Int. J. of Impact Eng., No. 1, pp 3-22 (1983). 
[4] Corbett, G.G., Reid, S. R. and Al-Hassani, S. T.," Resistance of steelconcrete sandwich tubes to penetration. ", Int. J. of Impact Eng., No. 9, pp191-203 (1990).

[5] Johnson, W., Chitkara, N. R. and Bex, B. A., "Characteristic features in the hole flanging and piercing of thin and thick circular plates using conical and ogival punches". No., 142, $15^{\text {th }}$ Int. MTDR Conf., pp. 695-701, Macmillan (1974).

[6] Backman, M. E. and Goldsmith, W. "The mechanics of penetration of projectiles into targets". Int. J. of Eng. sci. ,No.16, pp 1-99 (1978).

Table (1) Specimens details

\begin{tabular}{|c|c|c|c|c|c|c|}
\hline \multirow[b]{2}{*}{ Specimen } & \multicolumn{3}{|l|}{ Top plate } & \multicolumn{3}{|c|}{ Bottom plate } \\
\hline & $\begin{array}{l}\text { Plate } \\
\text { thickness }\end{array}$ & \begin{tabular}{|l} 
No. of \\
studs \\
per row
\end{tabular} & $\begin{array}{l}\text { Stud } \\
\text { spacing }\end{array}$ & $\begin{array}{l}\text { Plate } \\
\text { thickness }\end{array}$ & $\begin{array}{l}\text { No. of } \\
\text { studs per } \\
\text { row }\end{array}$ & $\begin{array}{l}\text { Stud } \\
\text { spacing }\end{array}$ \\
\hline Pilot test & $3 \mathrm{~mm}$ & 3 & $250 \mathrm{~mm}$ & 3 & 4 & $250 \mathrm{~mm}$ \\
\hline $\mathrm{DSC1}$ & $4 \mathrm{~mm}$ & 3 & $150 \mathrm{~mm}$ & $2 \mathrm{~mm}$ & 3 & $150 \mathrm{~mm}$ \\
\hline $\mathrm{DSC} 2$ & $2 \mathrm{~mm}$ & 3 & $150 \mathrm{~mm}$ & $4 \mathrm{~mm}$ & 3 & $150 \mathrm{~mm}$ \\
\hline DSC3 & $2 \mathrm{~mm}$ & 7 & $150 \mathrm{~mm}$ & $2 \mathrm{~mm}$ & 3 & $150 \mathrm{~mm}$ \\
\hline DSC4 & $2 \mathrm{~mm}$ & 3 & $150 \mathrm{~mm}$ & $2 \mathrm{~mm}$ & 7 & $150 \mathrm{~mm}$ \\
\hline DSC5 & $2 \mathrm{~mm}$ & 5 & $150 \mathrm{~mm}$ & $2 \mathrm{~mm}$ & 3 & $150 \mathrm{~mm}$ \\
\hline
\end{tabular}




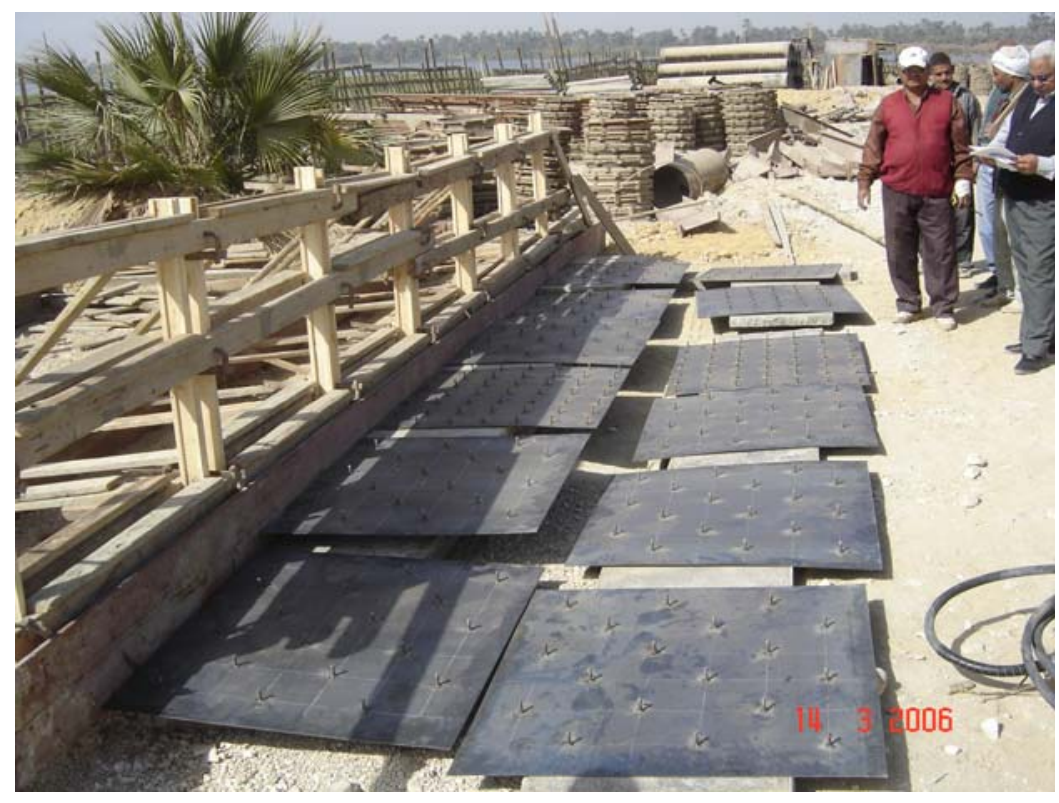

Fig. (1) Preparation of specimens
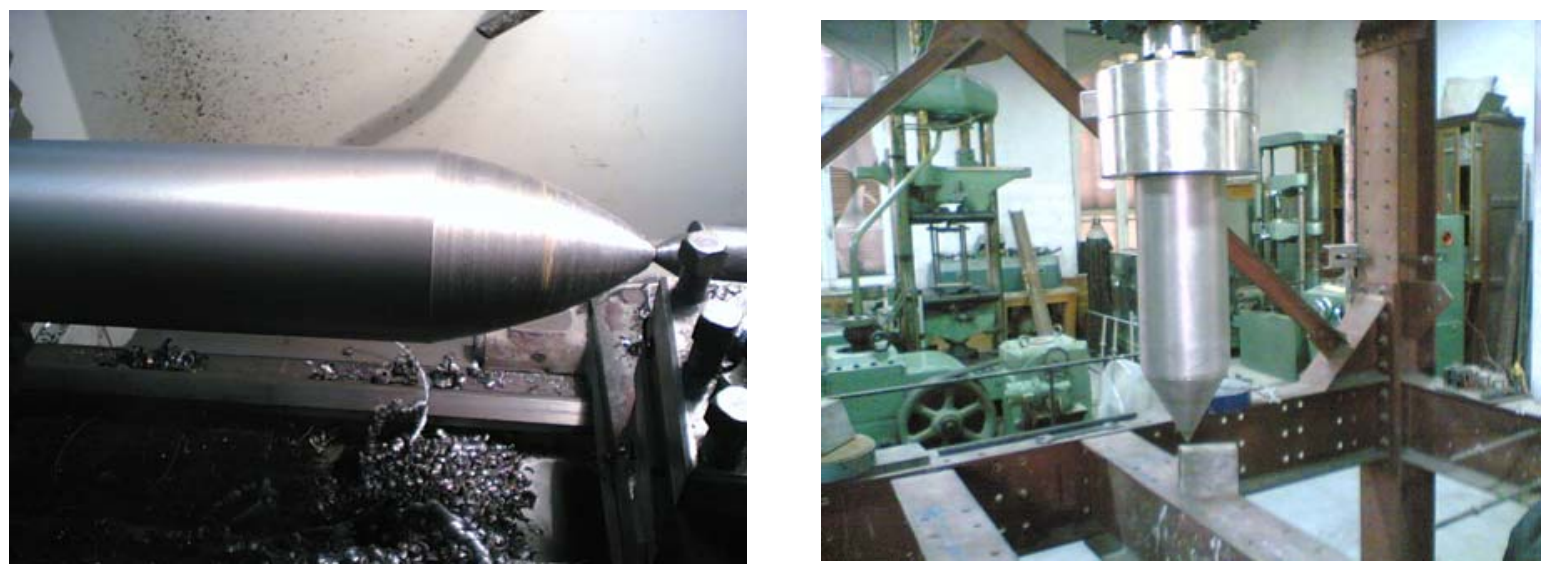

Fig. (2) Manufactured conical nose shape 


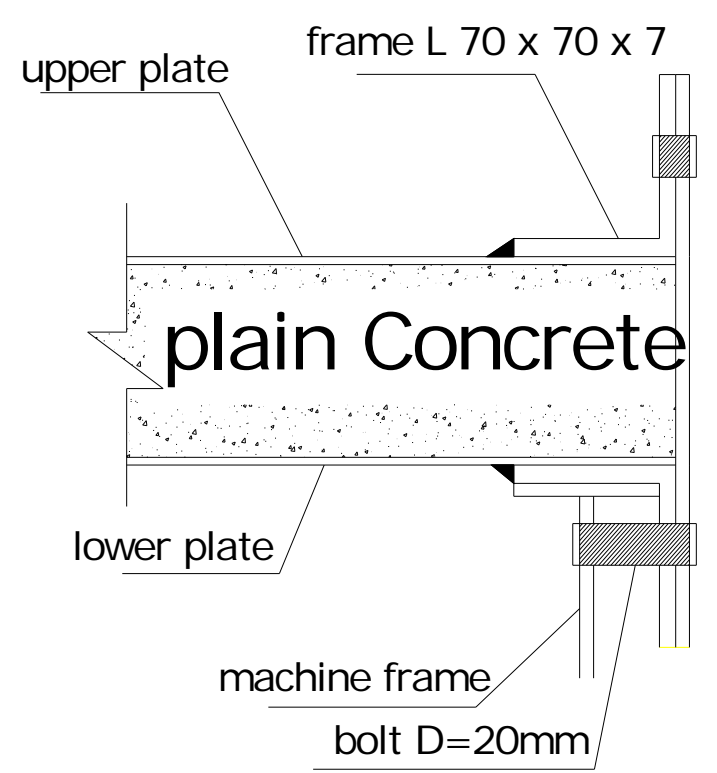

Fig. (3) Detail drawing of specimens clamping
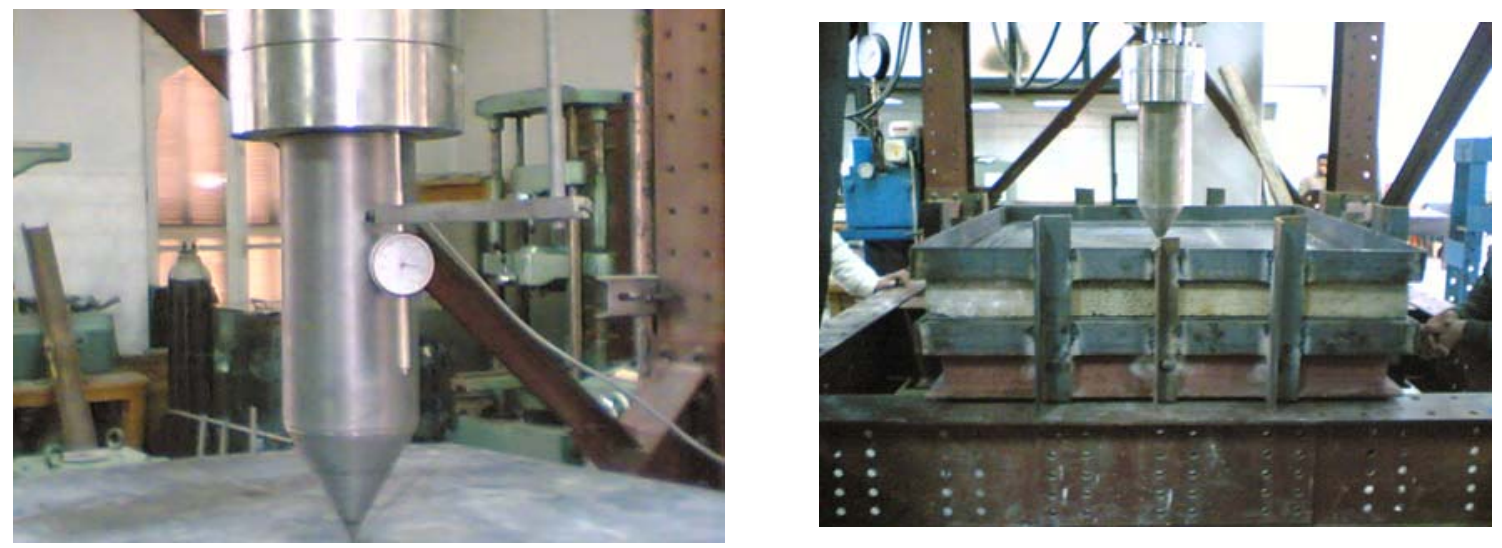

Fig. (4) Final test rig setup 

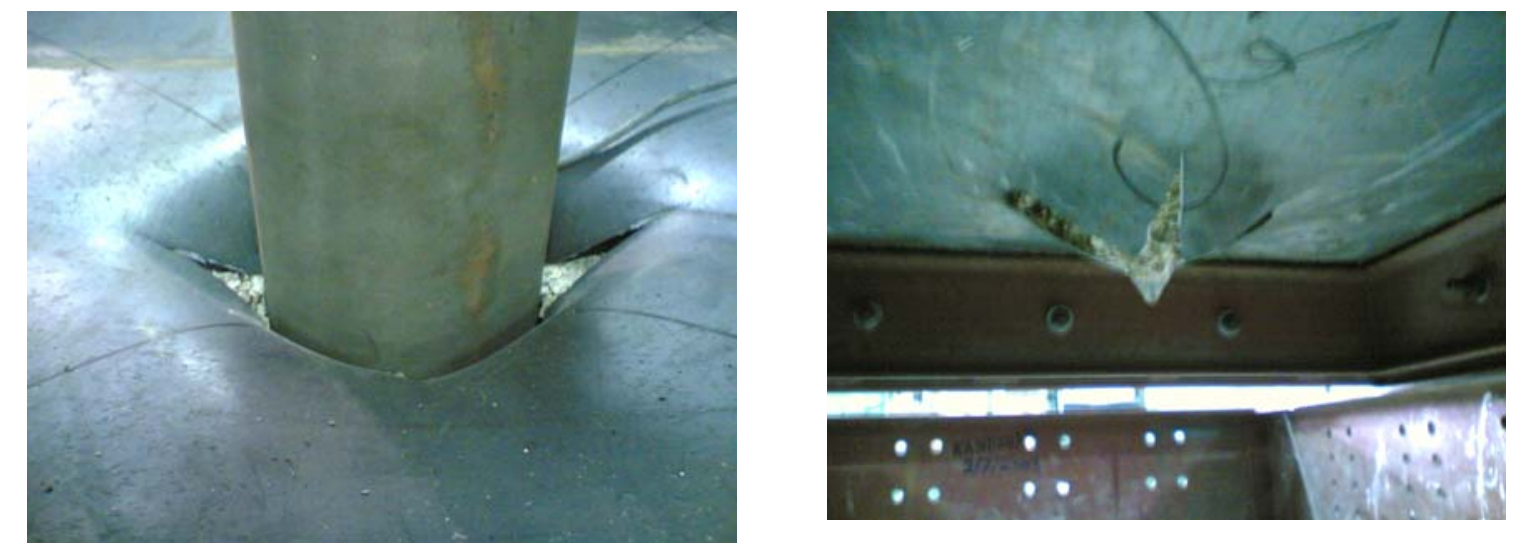

Fig. (5) Perforation of upper and lower steel skin

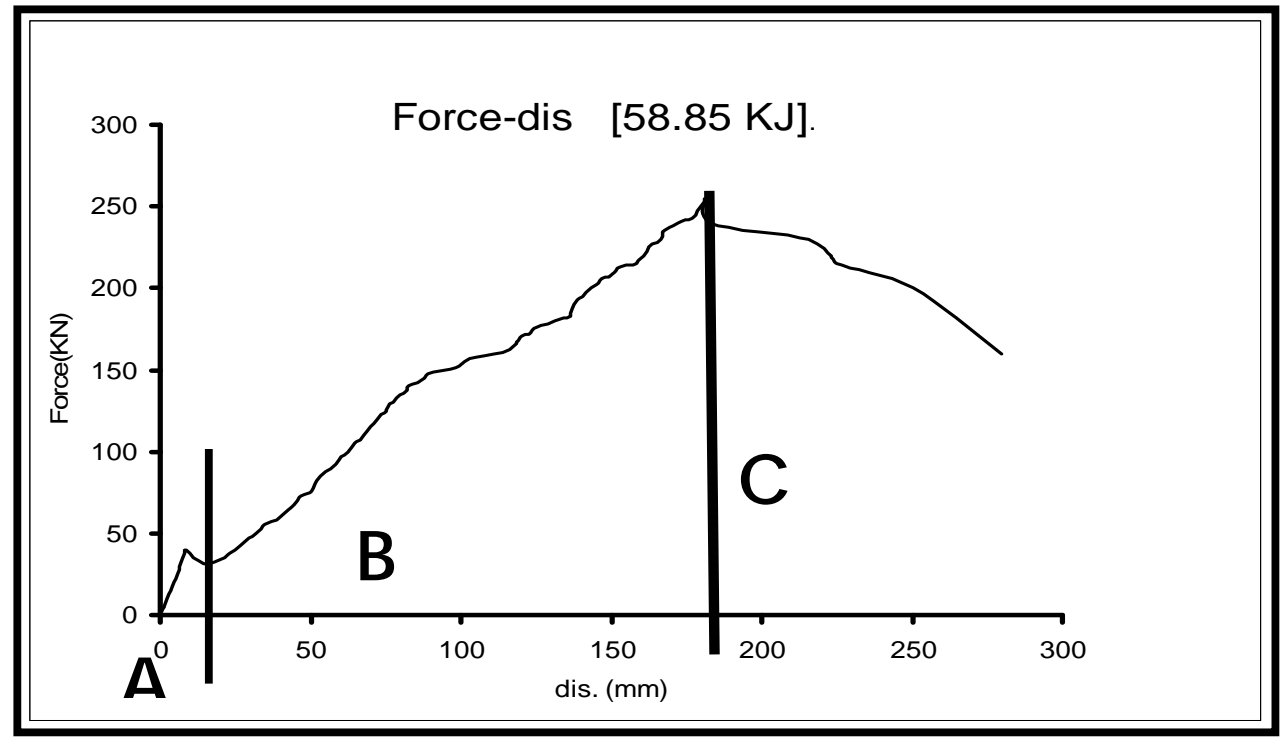

Fig. (6) Reaction - displacement relation for pilot-test specimen 

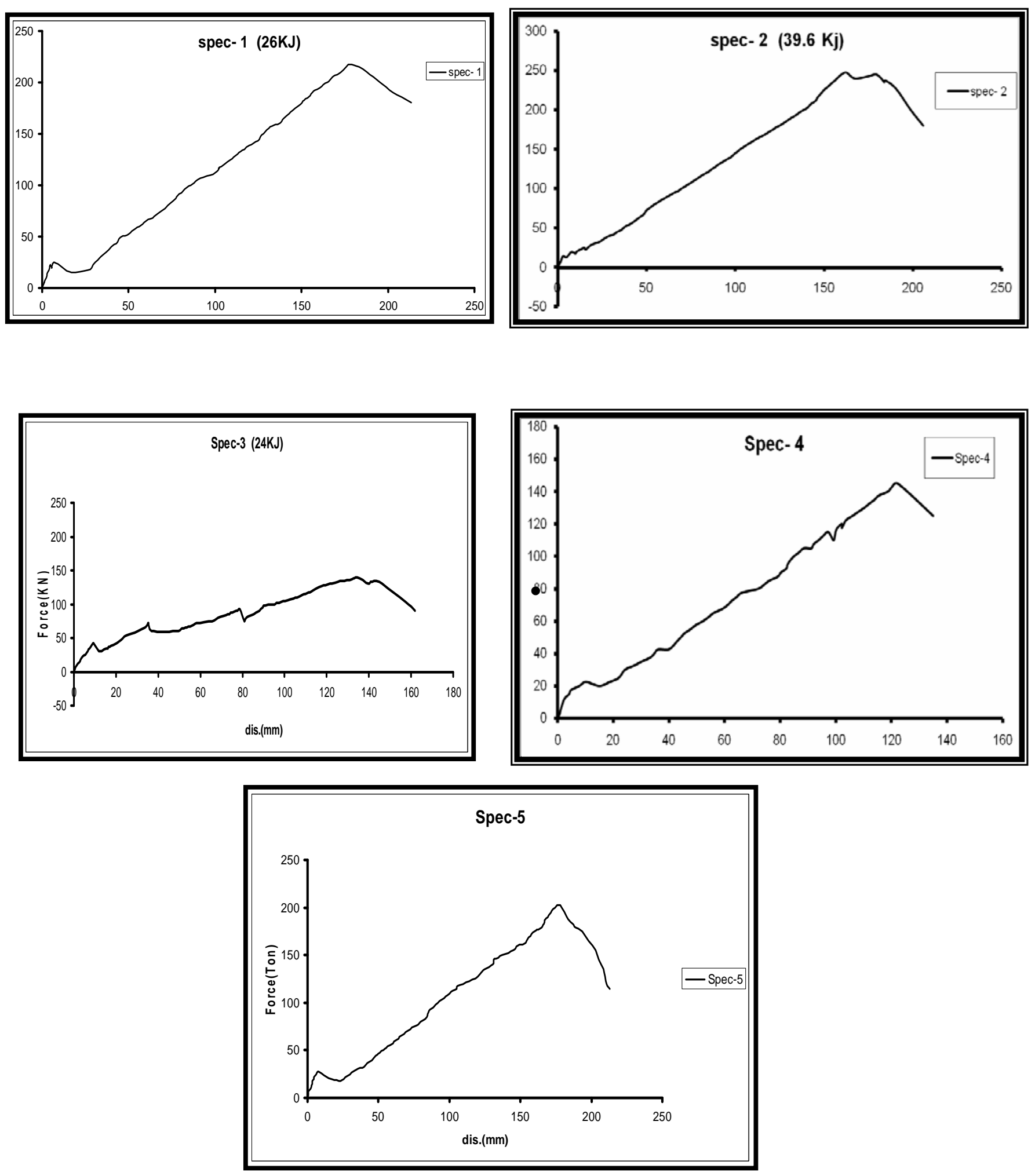

Fig. (7) Reaction - displacement relation for specimens (1, 2, 3, 4 and 5) respectively 


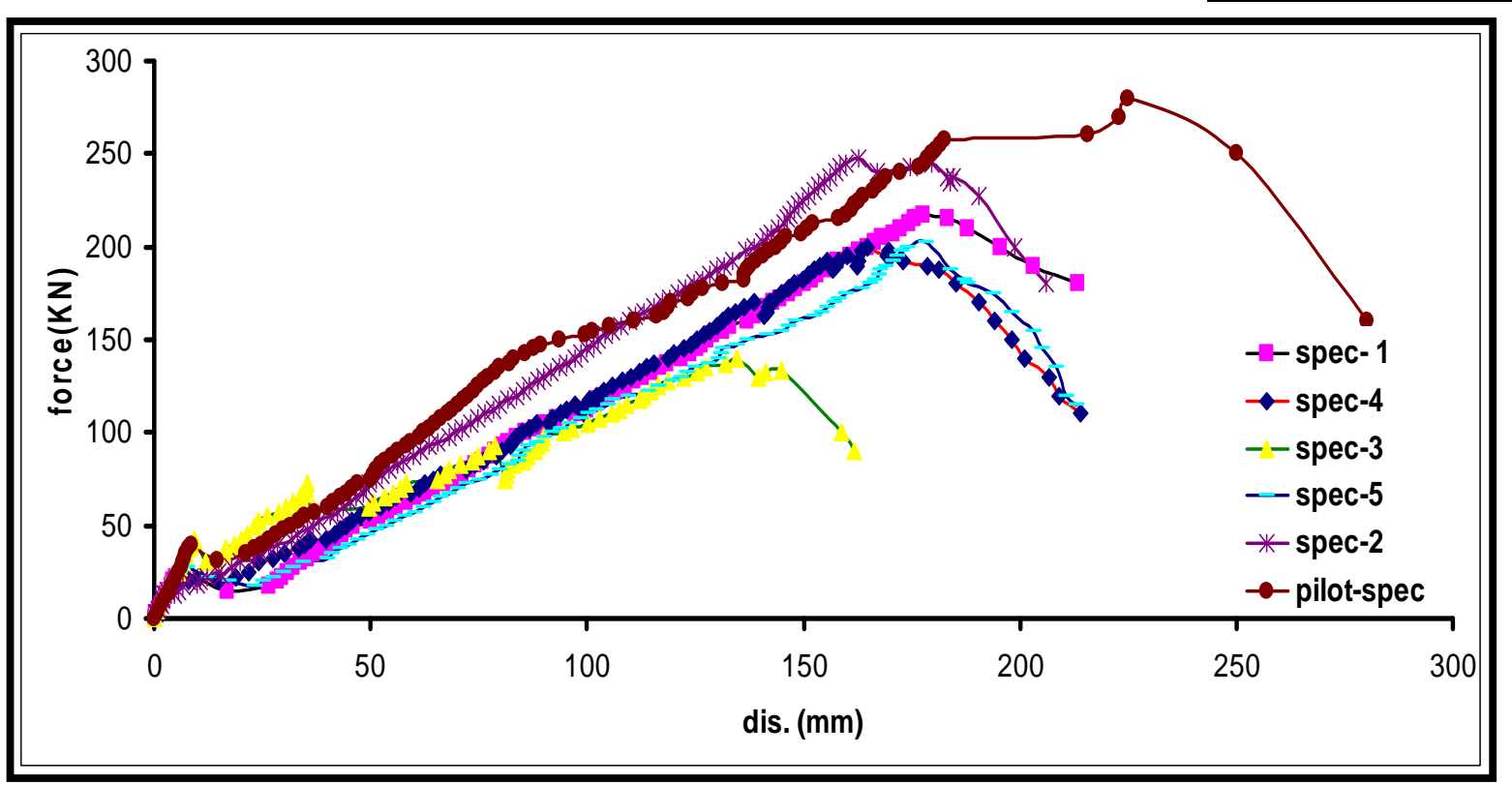

Fig. (8) Comparison of all specimens' results 